RESEARCH

\title{
Afamin predicts gestational diabetes in polycystic ovary syndrome patients preconceptionally
}

\author{
Angela Köninger ${ }^{1}$, Antonella lannaccone ${ }^{1}$, Ensar Hajder ${ }^{1}$, Mirjam Frank ${ }^{2}$, Boerge Schmidt ${ }^{2}$, \\ Ekkehard Schleussner ${ }^{3}$, Rainer Kimmig ${ }^{1}$, Alexandra Gellhaus ${ }^{1}$ and Hans Dieplinger ${ }^{4}$ \\ ${ }^{1}$ Department of Gynecology and Obstetrics, University of Duisburg-Essen, Essen, Germany \\ ${ }^{2}$ Institute for Medical Informatics, Biometry and Epidemiology (IMIBE), University of Duisburg-Essen, Essen, Germany \\ ${ }^{3}$ Department of Obstetrics, Jena University Hospital, Jena, Germany \\ ${ }^{4}$ Division of Genetic Epidemiology, Medical University of Innsbruck, Innsbruck, Austria \\ Correspondence should be addressed to H Dieplinger: hans.dieplinger@i-med.ac.at
}

\begin{abstract}
Background: Patients suffering from polycystic ovary syndrome (PCOS) are often insulin resistant and at elevated risk for developing gestational diabetes mellitus (GDM). The aim of this study was to explore afamin, which can be determined preconceptionally to indicate patients who will subsequently develop GDM. Serum concentrations of afamin are altered in conditions of oxidative stress like insulin resistance (IR) and correlate with the gold standard of IR determination, the HOMA index.

Methods: Afamin serum concentrations and the HOMA index were analyzed post hoc in 63 PCOS patients with live births. Patients were treated at Essen University Hospital, Germany, between 2009 and 2018. Mann-Whitney $U$ test, $T$ test, Spearman's correlation, linear regression models and receiver-operating characteristic (ROC) analyses were performed for statistical analysis.

Results: Patients who developed GDM showed significantly higher HOMA and serum afamin values before their pregnancy ( $P<0.001$, respectively). ROCs for afamin concentrations showed an area under the curve of 0.78 (95\% confidence interval $(\mathrm{Cl})$ $0.65-0.90)$ and of 0.77 (95\% Cl 0.64-0.89) for the HOMA index. An afamin threshold of $88.6 \mathrm{mg} / \mathrm{L}$ distinguished between women who will develop GDM and those who will not with a sensitivity of $79.3 \%$ and a specificity of $79.4 \%$. A HOMA index of 2.5 showed a sensitivity of $65.5 \%$ and a specificity of $88.2 \%$.

Conclusion: The HOMA index and its surrogate parameter afamin are able to identify prepregnant PCOS patients who are at risk to develop GDM. Serum afamin concentrations are independent of fasting status and therefore an easily determinable biomarker.
\end{abstract}

\section{Key Words}

- afamin

- insulin resistance

- polycystic ovary syndrome

- pre-pregnancy

- gestational diabetes mellitus

\section{Introduction}

Polycystic ovarian syndrome (PCOS) is a common disorder affecting up to $8 \%$ of women of reproductive age $(1,2)$. The syndrome is characterized by the presence of two of the three following diagnostic criteria: clinical and/or biochemical hyperandrogenism, sonographically determined polycystic ovaries with $\geq 12$ measured small follicles between two and nine millimeters in size and/or an ovarian volume greater than $10 \mathrm{~mL}$ and menstrual cycle disorders resulting in infertility (3). PCOS is also associated with several comorbidities resulting in longterm sequelae (4) like insulin resistance (IR) (5), obesity (6) and metabolic syndrome (7). https://ec.bioscientifica.com https://doi.org/10.1530/EC-19-0064 (c) 2019 The authors Published by Bioscientifica Ltd
This work is licensed under a Creative Commons Attribution-NonCommercial-NoDerivatives 4.0 Internationab ticense.ifica.com at $04 / 26 / 2023 \quad 07: 27: 31 \mathrm{Am}$ 
Although metabolic parameters are not included in the diagnostic criteria, they are thought to play crucial roles in the pathogenesis of the disease. Insulin enhances the effects of luteinizing hormone (LH) in granulosa cells and leads to androgen biosynthesis in PCOS patients in a synergistic way together with LH in vitro (8). IR is found in 50-95\% of PCOS patients irrespective of obesity (9). According to a study using the clamp technique, IR was even detected in $75 \%$ of lean and in $95 \%$ of obese PCOS patients (10).

PCOS patients are at elevated risk to develop pregnancy complications like gestational diabetes mellitus (GDM) $(11,12)$. IR, as determined with homeostasis model assessment (HOMA-IR) (13), when present before the beginning of a pregnancy seems to be the strongest factor associated with the development of GDM in patients suffering from PCOS, whereas other parameters like sexual hormone-binding protein (SHBG), fasting insulin and testosterone were not predictive after multivariate analysis $(14,15)$. During the course of a pregnancy, IR increases within a physiological frame. Consecutively, preexistent IR significantly enhances the risk of pathological glucose tolerance in pregnancy (16), resulting in GDM. GDM is associated with many fetal and maternal pathological conditions like macrosomia and birth injury $(17,18)$.

Currently, determination of IR, for example with HOMA-IR, is not included in PCOS management guidelines. To exclude diabetes mellitus in PCOS patients, a $75 \mathrm{~g}$ oral glucose test (OGTT) is recommended in obese women only (3). However, this test requires high-quality standards in performance and pre-analytics. In the light of a large proportion of lean PCOS patients also suffering from IR (10), the role of IR screening before the onset of pregnancy needs further research.

Since only scarce information is available concerning the preconceptional risk determination of pregnancy complications in PCOS patients, we here focus on afamin, an easily determinable biomarker that may indicate IR in pre-pregnant PCOS patients. In a previous study, we were able to demonstrate a strong association between IR and serum afamin concentrations in PCOS patients (19). Additionally, we demonstrated elevated afamin serum concentrations determined during the first and second trimester of pregnancy in patients with GDM (20).

The afamin gene is a member of the albumin gene family localized on chromosome 4 (21). Afamin has been postulated to bind vitamin E in extravascular fluids (22). Vitamin E is an important antioxidant (23) and afamin seems to play a crucial role in oxidative stress-related anti-apoptotic cellular processes (24). Impaired glucose tolerance, hyperandrogenism and oxidative stress were shown to be strongly dependent on each other in PCOS patients $(25,26,27)$.

In this study, we explored the association between HOMA-IR and afamin serum concentrations in PCOS patients prior to pregnancy and evaluated the ability of both parameters to predict the development of GDM in these patients.

\section{Subjects and methods}

\section{Patients and control subjects}

PCOS patients $(n=63)$ who gave birth were investigated post hoc. We consecutively included all PCOS patients who were treated at the Department of Gynecology and Obstetrics, University Hospital Essen, between 2009 and 2018, became pregnant and from whom pre-pregnant serum samples as well as knowledge about pregnancy outcome were available. We included only women with live births. Patients who were treated with metformin during their pregnancy and were not diagnosed as having GDM were excluded. Four patients had twins (two with GDM, two without GDM) and 59 patients had singleton pregnancies. Patients delivered between gestational day 180 and day 289. Mild late-onset preeclampsia was observed in 3/63 patients. None of the patients delivered a small for gestational age baby. All patients who suffered from PCOS-related sterility were treated as follows: intake of metformin $(n=3)$, therapy with antiestrogens $(n=13)$ or recombinant FSH (follicle-stimulating hormone) $(n=37)$, laparoscopic ovarian drilling $(n=1)$, in vitro fertilization (IVF) $(n=4)$ and no therapeutic intervention $(n=5)$.

Informed written consent was obtained from all patients. The study was approved by the Research Ethics Committee of the University of Essen, Germany (No. 11-4688).

\section{GDM diagnosis}

Information on pregnancy outcome was available from medical records. GDM was diagnosed according to currently used guidelines published by the Deutsche Gesellschaft für Gynäkologie und Geburtshilfe (DGGG) (28). Patients without risk factors for GDM underwent a $50 \mathrm{~g}$ OGTT, followed by a $75 \mathrm{~g}$ OGTT in cases where glucose was $\geq 135 \mathrm{mg} / \mathrm{dL}$ after $1 \mathrm{~h}$ as determined by the $50 \mathrm{~g}$ OGTT. In patients at high risk for GDM (e.g. obesity, hyperandrogenism) a $75 \mathrm{~g}$ OGTT instead of a $50 \mathrm{~g}$ OGTT was recommended. Threshold limits were $92 \mathrm{mg} / \mathrm{dL}$ in fasting state, $180 \mathrm{mg} / \mathrm{dL}$ after $1 \mathrm{~h}$ and $153 \mathrm{mg} / \mathrm{dL}$ after $2 \mathrm{~h}$. GDM was diagnosed if at least one test was pathological (28). This was the case in 29 (46\%) pregnancies, whereas in
This work is licensed under a Creative Commons Attribution-NonCommercial-NoDerivatives 4.0 denternationab sicense.ifica com at 04/26/2023 07:27:31AM 
34 (54\%) pregnant women, no GDM was diagnosed. Of 29 GDM patients, six were treated with diet and 23 with insulin.

\section{PCOS diagnosis}

PCOS was diagnosed according to the Rotterdam ESHRE/ ASRM-Sponsored PCOS Consensus Workshop Group 2003 (3). Patients presented for blood sampling and a transvaginal scan between the second and the fifth day of their menstrual cycle or after induction of an artificial bleeding by short-time progestin intake in cases of amenorrhea. Real-time ultrasound measurements were performed using a 7-MHz transducer (Voluson E8, General Electric Systems; IU22, Philips Healthcare). Oligomenorrhea was defined as a menstrual cycle longer than 35 days and amenorrhoea as cycles with a duration of more than 3 months. Clinical or biochemical signs of hyperandrogenism were diagnosed with a FerrimanGallway score $>7$ (29) or obvious acne or alopecia (30) or an increased total testosterone (normal range $0.5-2.6 \mathrm{nmol} / \mathrm{L}$ ) and/or DHEAS (normal range 6-123 $\mu \mathrm{g} / \mathrm{dL}$ ) and/or androstendione (normal range $0.3-3.3 \mathrm{ng} / \mathrm{mL}$ ). ACTH test and genetic testing were performed in cases with suspected 21-hydroxylase deficiency. Patients with confirmed adrenogenital syndrome, pituitary, adrenal or other ovarian diseases were excluded from the study. None of the participants had taken hormonal contraceptives for less than 3 months before they participated in the study.

\section{Blood sampling}

Blood $(29.7 \mathrm{~mL})$ was collected from each patient after a 12-h fasting period into S-Monovette tubes (Sarstedt AG \& Co.) for serum analysis of insulin, luteinizing hormone (LH), follicle-stimulating hormone (FSH), total testosterone, sex hormone-binding globulin (SHBG), androstendione, anti-Mullerian hormone (AMH) and afamin. Blood samples were stored at $4^{\circ} \mathrm{C}$ and processed within $4 \mathrm{~h}$ to avoid blood cell lysis. Serum was obtained by low-speed centrifugation, frozen immediately and kept at $-80^{\circ} \mathrm{C}$ until analysis. Also collected was $2.7 \mathrm{~mL}$ blood into $2.7 \mathrm{ml}$ Flourid/EDTA Monovette tubes for plasma glucose determination, which was performed immediately after blood collection. Plasma was obtained by low-speed centrifugation. IR was calculated using the homeostasis model assessment (HOMA) (13).

\section{Biochemical analyses}

Chemiluminescence immunoassay systems were used to analyze LH, FSH, testosterone (ADVIA Centaur,
Siemens Healthcare Diagnostics), androstendione, SHBG and insulin (Immulite $2000 \mathrm{XPi}$, Siemens Healthcare Diagnostics). Free testosterone index was calculated as ((total testosterone/SHBG) × 100). Glucose was determined photometrically (ADVIA Centaur, Siemens Healthcare Diagnostics). Intra-assay variation was $<5 \%$ and interassay variation was $<8 \%$ for all parameters.

AMH concentrations were determined with the Gen II AMH immunoassay (Beckman Coulter), according to a revised protocol (31) and following the manufacturer's instructions. Intra- and inter-assay variations were $<6 \%$.

Afamin was measured with a commercially available sandwich ELISA (BioVendor, Brno, Czech Republic) using two different monoclonal antibodies against human afamin as modified from a previously described protocol (32). Recombinantly expressed and purified human afamin served as assay standard. Intra- and interobservation variation was 3.3 and $6.2 \%$, respectively, at a mean concentration of $73 \mathrm{mg} / \mathrm{L}(32)$.

\section{Statistical analyses}

Study population characteristics are shown as medians with interquartile ranges (IQR) and means \pm SD. $T$ test and the Mann-Whitney $U$ test were used to compare the parameters of interest between the subgroups. Spearman's correlation coefficient was calculated to determine the relationship between afamin concentrations and HOMA-IR. To compare afamin and HOMA-IR between subgroups adjusted for maternal age and BMI as potential confounder, multiple linear regression models were used including GDM status as independent variable and maternal age and BMI as covariate to estimate confounder-adjusted least-squares means with 95\% CIs as marginal averages.

Receiver-operating characteristic (ROC) analysis was performed for HOMA-IR and afamin concentrations to test their ability to discriminate between patients who will and those who will not develop GDM. We additionally calculated ROCs for SHBG, the LH/FSH ratio and the $\mathrm{BMI}$, since these parameters also differed between the subgroups. The area under the curve (AUC) estimates were calculated to indicate the probability of accurately discriminating between the two subgroups. Differences in AUC values were compared by means of DeLong's test for correlated ROC curves. The optimal cut-off value, that is, the threshold that maximizes the sum of (sensitivity + specificity) was calculated according to Youden (33). All statistical analyses were performed with the R statistical package, version 3.4.0 (34).

This work is licensed under a Creative Commons Attribution-NonCommercial-NoDerivatives 4.0 Internationab bicense.ifica com at 04/26/2023 07:27:31AM 
Table 1 Patient characteristics.

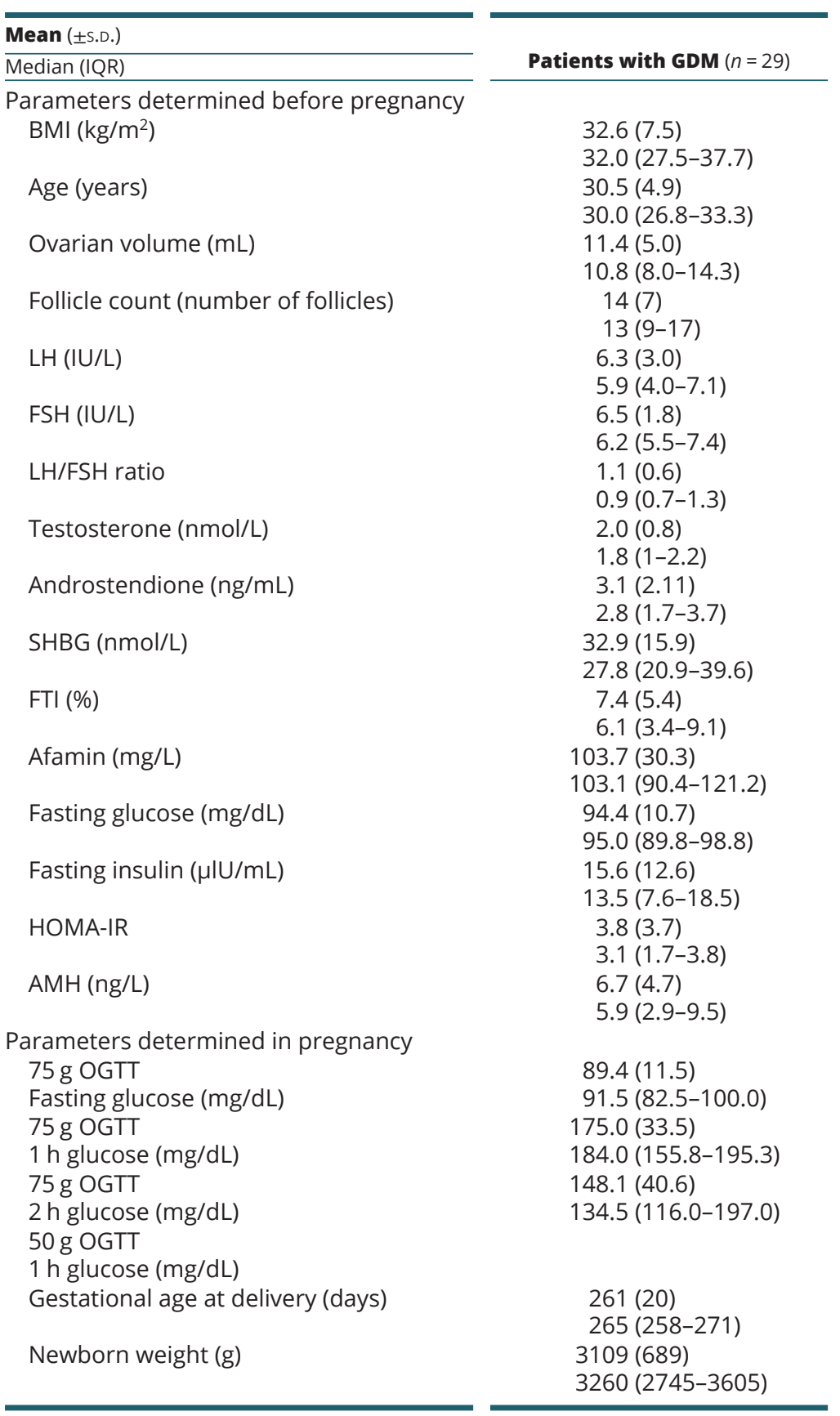

\begin{tabular}{|c|c|}
\hline Patients without GDM $(n=34)$ & $P$ value \\
\hline $\begin{array}{l}26.0(6.2) \\
25.7(21.6-29.1)\end{array}$ & $<0.001$ \\
\hline $\begin{array}{l}28.7(5.0) \\
29.5(24.0-32.0)\end{array}$ & 0.163 \\
\hline $\begin{array}{l}13.9(5.0) \\
13.8(10.1-17.0)\end{array}$ & 0.065 \\
\hline $\begin{array}{l}18(10) \\
14(12-20)\end{array}$ & 0.125 \\
\hline $\begin{array}{l}8.2(3.9) \\
7.9(5.4-9.9)\end{array}$ & 0.042 \\
\hline $\begin{array}{l}5.8(1.9) \\
5.9(4.9-7.0)\end{array}$ & 0.141 \\
\hline $\begin{array}{l}1.6(0.9) \\
1.4(0.9-1.8)\end{array}$ & 0.005 \\
\hline $\begin{array}{l}1.9(0.8) \\
1.7(1.3-2.4)\end{array}$ & 0.692 \\
\hline $\begin{array}{l}3.1(1.3) \\
2.7(2.2-3.9)\end{array}$ & 0.684 \\
\hline $\begin{array}{l}56.5(30.2) \\
56.8(29.3-76.2)\end{array}$ & 0.002 \\
\hline $\begin{array}{l}4.9(3.5) \\
3.6(2.3-5.8)\end{array}$ & 0.058 \\
\hline $\begin{array}{l}76.4(25.9) \\
75.5(56.8-86.8)\end{array}$ & $<0.001$ \\
\hline $\begin{array}{l}84.8(8.2) \\
84.0(77.5-88.8)\end{array}$ & $<0.001$ \\
\hline $\begin{array}{l}6.5(5.9) \\
4.0(2.5-9.7)\end{array}$ & $<0.001$ \\
\hline $\begin{array}{l}1.5(1.4) \\
0.9(0.5-2.1)\end{array}$ & $<0.001$ \\
\hline $\begin{array}{l}8.9(5.3) \\
7.8(5.6-11.3)\end{array}$ & 0.109 \\
\hline $\begin{array}{l}76.1(10.7) \\
78.0(66.0-84.0)\end{array}$ & 0.012 \\
\hline $\begin{array}{l}121.6(33.0) \\
124.0(95.0-145.0)\end{array}$ & 0.001 \\
\hline $\begin{array}{l}94.3(25.4) \\
86.5(75.0-112.5) \\
90.0(11.2) \\
89.0(81.5-98.5)\end{array}$ & 0.003 \\
\hline $\begin{array}{l}266(22) \\
273(252-280)\end{array}$ & 0.051 \\
\hline $\begin{array}{l}3046(811) \\
3215(2435-3620)\end{array}$ & 0.84 \\
\hline
\end{tabular}

Values are presented as means with S.D. and medians with interquartile ranges (IQR).

$\mathrm{AMH}$, anti-Mullerian hormone; BMI, body mass index; FSH, follicle-stimulating hormone; FTI, free testosterone index; LH, luteinizing hormone; OGTT, oral glucose tolerance test; SHBG, sexual hormone-binding protein.

\section{Results}

Patient characteristics are shown in Table 1. GDM patients presented with significantly higher concentrations of afamin $(P<0.001$, Fig. 1$)$, HOMA-IR $(P<0.001$, Fig. 2$)$ and BMI $(P<0.001)$ as well as significantly lower levels of LH $(P=0.04), \mathrm{LH} / \mathrm{FSH}$ ratio $(P=0.005)$ and SHBG
$(P=0.002)$ than did controls. There was a significant correlation between HOMA-IR and afamin concentrations (Spearman's correlation coefficient $r=0.61 ; P<0.001$ ).

After adjusting for maternal age, afamin serum concentrations were significantly higher in GDM patients (mean $104.0 \mathrm{mg} / \mathrm{L}$; 95\% CI 93.4-114.6) than in controls (mean 76.1 mg/L; 95\% CI 66.4-85.9; $P=0.0003$ ). https://ec.bioscientifica.com https://doi.org/10.1530/EC-19-0064 (c) 2019 The authors Published by Bioscientifica Ltd
This work is licensed under a Creative Commons Attribution-NonCommercial-NoDerivatives 4.0 elnternationad ticense ifica . com at 04/26/2023 07:27:31AM 


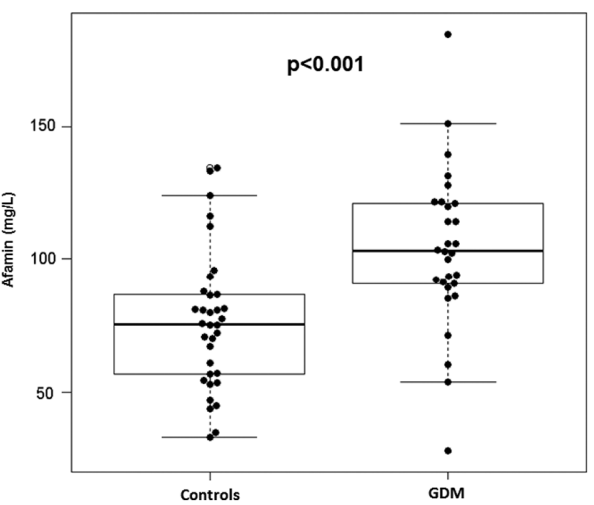

Figure 1

Box/scatter plots illustrating the distribution of afamin serum concentrations $(\mathrm{mg} / \mathrm{L})$ in pre-pregnant PCOS patients without $(n=34)$ and with gestational diabetes mellitus $(n=29)$.

Adjustment for BMI showed almost identical results for GDM patients (mean $99.4 \mathrm{mg} / \mathrm{L} ; 95 \%$ CI 70.3-89.9) and controls (mean $80.1 \mathrm{mg} / \mathrm{L}$; 95\% CI 88.6-110.1; $P=0.02$, Fig. 3). HOMA-IR was also higher in GDM patients (mean 3.8; 95\% CI 2.8-4.9) than in controls (mean 1.5; 95\% CI 0.6-2.4; $P=0.001$ ) after adjusting for maternal age. After adjustment for BMI, HOMA-IR no longer showed a significant difference between GDM patients (mean 3.3; 95\% CI 2.3-4.3) and controls (mean 2.0; 95\% CI 1.1-2.9; $P=0.07$, Fig. 4).

ROCs for afamin concentrations showed an AUC of 0.78 (95\% CI 0.65-0.90) and of 0.77 (95\% CI 0.64-0.89) for the HOMA index (Table 2, Figs 5 and 6). An afamin threshold of $88.6 \mathrm{mg} / \mathrm{L}$ distinguished between women who developed GDM and those who did not with a sensitivity of $79.3 \%$ and a specificity of $79.4 \%$. A HOMA index of 2.5 showed a sensitivity of $65.5 \%$ and a specificity of $88.2 \%$. The AUC did not differ significantly between afamin and

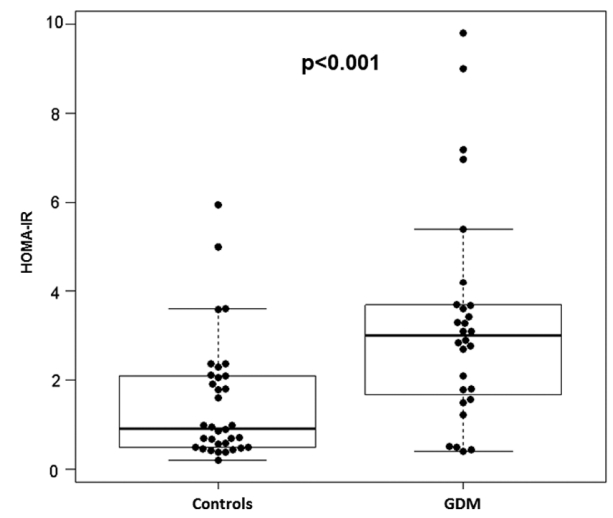

Figure 2

Box/scatter plots illustrating the distribution of HOMA-IR (homeostasis model assessment of insulin resistance) in pre-pregnant PCOS patients without $(n=34)$ and with gestational diabetes mellitus $(n=29)$.

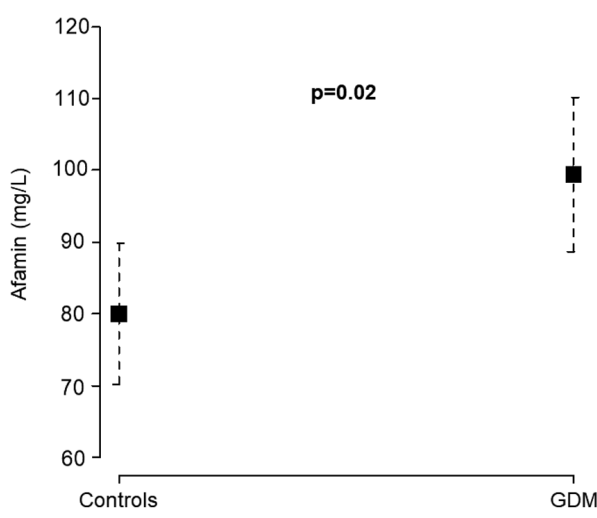

Figure 3

Serum concentrations of afamin among pre-pregnant patients without $(n=34)$ and with gestational diabetes mellitus $(n=29)$, adjusted for maternal age and body mass index (BMI).

HOMA-IR $(P=0.84)$, indicating a comparable potency for predicting the development of GDM using either of these two parameters.

Since SHBG, BMI and LH/FSH ratio differed significantly between patients developing GDM and controls, we additionally performed ROC analyses of these parameters. Their AUC were similar compared to the AUC for afamin or HOMA (Table 2).

\section{Discussion}

The aim of this study was to evaluate the predictive potency of afamin concentrations and the HOMA-IR to predict GDM in PCOS patients preconceptionally. We were able to demonstrate that the risk to develop GDM is strongly associated with increased preconceptional afamin serum concentrations and HOMA-IR in PCOS

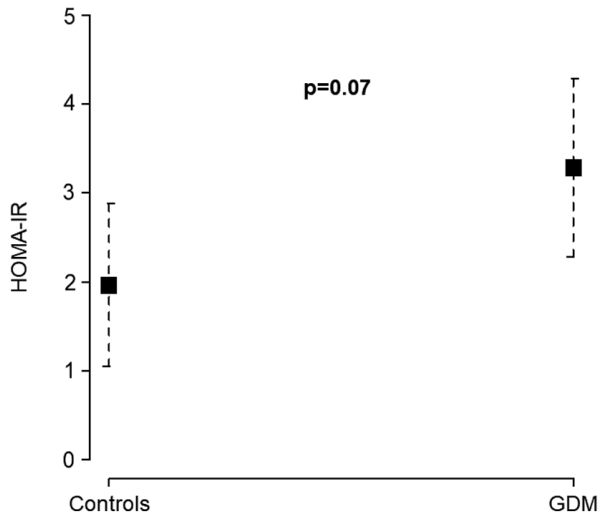

Figure 4

HOMA-IR (homeostasis model assessment of insulin resistance) among pre-pregnant patients without $(n=34)$ and with gestational diabetes mellitus ( $n=29)$, adjusted for maternal age and body mass index (BMI). 
Table 2 Results of ROC analyses.

\begin{tabular}{lll}
\hline Variable & AUC $(95 \% \mathrm{Cl})$ \\
\hline Afamin & & $0.78(0.65-0.90)$ \\
HOMA index & $0.77(0.64-0.89)$ \\
SHBG & $0.74(0.61-0.86)$ \\
BMI & $0.76(0.63-0.88)$ \\
LH/FSH ratio & $0.71(0.57-0.84)$ \\
\hline
\end{tabular}

\begin{tabular}{c}
\hline Threshold \\
\hline $88.6 \mathrm{mg} / \mathrm{L}$ \\
2.5 \\
$41.4 \mathrm{nmol} / \mathrm{L}$ \\
$27.6 \mathrm{~kg} / \mathrm{m}^{2}$ \\
0.9
\end{tabular}

\begin{tabular}{c}
\hline Specificity $(\%)$ \\
\hline 79.4 \\
88.2 \\
65.6 \\
67.7 \\
83.9 \\
\hline
\end{tabular}

\begin{tabular}{c}
\hline Sensitivity $(\%)$ \\
\hline 79.3 \\
65.5 \\
77.8 \\
75.9 \\
53.6
\end{tabular}

BMI, body mass index; FSH, follicle-stimulating hormone; LH, luteinizing hormone; SHBG, sexual hormone-binding protein.

patients. Preconceptional values of 2.5 for HOMA-IR and $88.6 \mathrm{mg} / \mathrm{L}$ for afamin concentrations showed the best sensitivity and specificity in predicting the development of GDM.

Patients who developed GDM also had higher BMI, SHBG concentrations und LH/FSH ratio preconceptionally than did pregnant women without GDM. However, the potency of these parameters to predict GDM was lower than that of afamin or HOMA-IR.

Several further authors were able to demonstrate that preconceptional IR is a significant risk factor for developing GDM in non-PCOS (16) as well as in PCOS patients $(35,36)$. In uncomplicated pregnancies, IR increases physiologically and is necessary for proper materno-fetal glucose transfer. In the case of elevated pre-pregnancy IR, pathological glucose tolerance of the mother with increased glucose transfer to the fetus can occur. The impaired obstetrical and neonatal outcomes were convincingly demonstrated in the HAPO trial (18).

Knowledge about the occurrence of increased IR and the subsequent early detection and treatment of GDM is advantageous with regard to early pregnancy loss $(37,38)$ and perinatal outcome $(39)$. Consequently, the determination of pathological glucose tolerance should be monitored early in pregnancy in women with prepregnant IR. Otherwise, the performance of a glucose tolerance test in the second trimester may ignore GDM that is already present before the 24th week of pregnancy.

Our findings are in accordance with those published by de Wilde et al. (14). Those authors studied 72 PCOS patients, of whom 31\% developed GDM. After multivariate analysis, HOMA-IR was the only significant predictor of GDM in pre-pregnant PCOS patients. In the cited study, median preconceptional HOMA-IR was 2.1 in the group of GDM patients. Median HOMA-IR in our study was 3.1. However, the participants with GDM in the study by de Wilde et al., were obviously leaner (median BMI: $27.4 \mathrm{~kg} / \mathrm{m}^{2}$; IQR $\left.22.7-33.8\right)$ than were those in our cohort (median BMI: $32.0 \mathrm{~kg} / \mathrm{m}^{2}$; IQR 27.5-37.7).

We excluded GDM patients from our cohort who had a history of pregnancy complications like recurrent early miscarriages or fetal loss in the second trimester and therefore received metformin during the first trimester of pregnancy. In observational studies it was shown that the intake of metformin may reduce the risk of suffering pregnancy complications including GDM (38), although this remains controversial $(40,41)$. Nevertheless, exclusion of these patients may be a bias resulting in an altered subgroup distribution with a higher mean HOMA-IR compared to the study of de Wilde et al. (14). In accordance with this study (14), the newborn weight of our participants' babies did not differ between women with and without GDM. Very intensive care with straight glucose control was offered to our patients with GDM, which may be an explanation for the low rate of large for gestational age babies in our study population.

The exact role of afamin in contributing to impaired glucose tolerance and metabolic syndrome development is not fully clarified. Increased serum afamin levels were

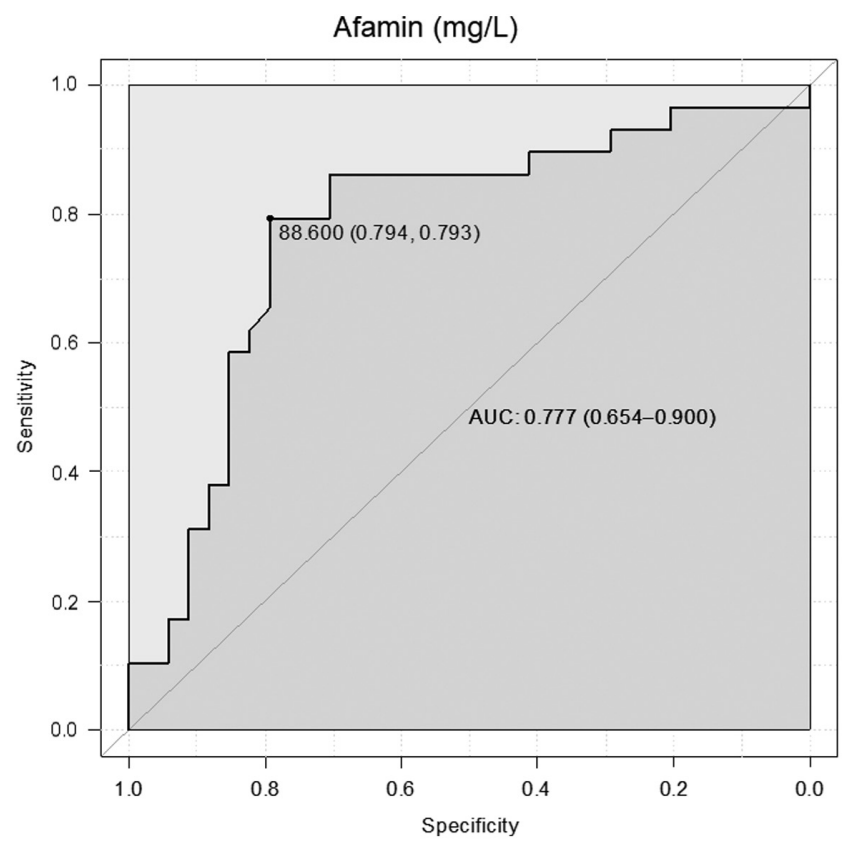

Figure 5

Receiver operating characteristic (ROC) analysis of serum afamin concentrations showing the discrimination between patients who will develop gestational diabetes and those who will not. 


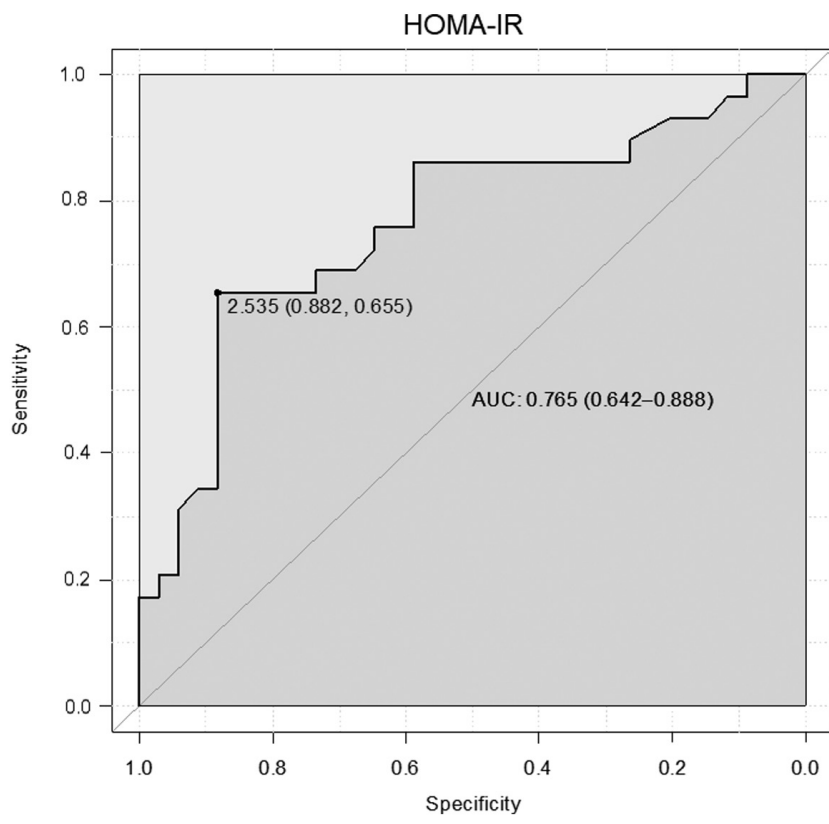

Figure 6

Receiver operating characteristic (ROC) analysis of HOMA-IR (homeostasis model assessment of insulin resistance) showing the discrimination between patients who will develop gestational diabetes (GDM) and those who will not.

shown to indicate conditions with elevated risk for metabolic syndrome like dyslipidemia, hypertension, glucose tolerance disorders and obesity in an animal model as well as in large human population-based cohorts $(42,43)$. Evidence was provided for a direct influence of afamin on glucose metabolism in vitro (44). The most important association between impaired glucose tolerance and afamin, however, seems to be founded in the known interplay between oxidative stress, chronic inflammation and IR (43). From clinical research with elevated afamin concentrations in distinct clinical conditions as described above, a functional role of afamin in oxidative stress situations and chronic inflammation is hypothesized. However, a functional relation between afamin and the antioxidant vitamin $\mathrm{E}$ in human plasma has not yet been demonstrated (45).

Since afamin concentrations increase linearly with gestational age (46), their determination and interpretation in pregnancy require defined gestational age-specific thresholds that are not yet exactly described. Determination before pregnancy, in contrast, does not depend on gestational age-specific alterations of the parameter.

As a limitation of this study it should be mentioned that the time between afamin determination and conception differed between patients. Weight gain or loss may have contributed to afamin concentrations immediately before conception.

In summary, IR is associated with oxidative stress in PCOS patients (26). This condition seems to be reflected by increased afamin serum concentrations (19). Afamin is therefore able to identify PCOS patients with IR and an elevated risk to develop GDM. Since serum afamin concentrations are independent of sex, age and fasting status (32), it is an easily determinable biomarker. In contrast, determination of HOMA-IR needs precise fasting conditions and defined pre-analytical standards to avoid glycolysis. Since HOMA-IR is a valid method for diagnosing IR $(13,47)$, afamin probably will not replace it, but may act as a surrogate marker for IR screening.

\section{Conclusion}

PCOS patients are at elevated risk for pregnancy complications like GDM. Pre-pregnant impaired glucose tolerance seems to be the major risk factor. The gold standard for IR determination is HOMA-IR. The afamin serum concentration is a surrogate parameter for IR, correlates strongly with HOMA-IR and showed the highest AUC in distinguishing between pre-pregnant PCOS patients who will develop GDM and those who will not. Therefore, afamin appears to be a suitable and easily determinable biomarker in pre-pregnant PCOS patients indicating an elevated risk for GDM.

\section{Declaration of interest}

The authors declare that there is no conflict of interest that could be perceived as prejudicing the impartiality of the research reported.

\section{Funding}

This work was supported by aid provided by the University of DuisburgEssen to A K and by the Austrian Research Fund (P19969-B11) to H D.

\section{Acknowledgments}

The authors thank the laboratory staff and the nurses of Essen University Hospital, Department of Gynecology and Obstetrics, for technical assistance and data documentation. They are also indebted to Johanna van Halteren and Caroline Schwenk for data collection and to Mary Heaney Margreiter for English language editing and critical reading of the manuscript.

\section{References}

1 Azziz R. PCOS: a diagnostic challenge. Reproductive Biomedicine Online 20048 644-648. (https://doi.org/10.1016/S1472-6483(10)61644-6)

2 Michelmore KF, Balen AH, Dunger DB \& Vessey MP. Polycystic ovaries and associated clinical and biochemical features in young 
women. Clinical Endocrinology 199951 779-786. (https://doi. org/10.1046/j.1365-2265.1999.00886.x)

3 The Rotterdam ESHRE/ASRM-sponsored PCOS consensus workshop group. Revised 2003 consensus on diagnostic criteria and long-term health risks related to polycystic ovary syndrome (PCOS). Human Reproduction 200419 41-47. (https://doi.org/10.1093/humrep/ deh098)

4 Fauser BC, Tarlatzis BC, Rebar RW, Legro RS, Balen AH, Lobo R, Carmina E, Chang J, Yildiz BO, Laven JS, et al. Consensus on women's health aspects of polycystic ovary syndrome (PCOS): the Amsterdam ESHRE/ASRM-Sponsored 3rd PCOS Consensus Workshop Group. Fertility and Sterility 201297 28.e25-38.e25. (https://doi. org/10.1016/j.fertnstert.2011.09.0240)

5 Baillargeon JP \& Nestler JE. Commentary: polycystic ovary syndrome: a syndrome of ovarian hypersensitivity to insulin? Journal of Clinical Endocrinology and Metabolism 200691 22-24. (https://doi. org/10.1210/jc.2005-1804)

6 Hahn S, Tan S, Elsenbruch S, Quadbeck B, Herrmann BL, Mann K $\&$ Janssen OE. Clinical and biochemical characterization of women with polycystic ovary syndrome in North Rhine-Westphalia. Hormone and Metabolic Research 200537 438-444. (https://doi. org/10.1055/s-2005-870236)

7 Hahn S, Tan S, Sack S, Kimmig R, Quadbeck B, Mann K \& Janssen OE. Prevalence of the metabolic syndrome in German women with polycystic ovary syndrome. Experimental and Clinical Endocrinology \& Diabetes 2007115 130-135. (https://doi.org/10.1055/s-2007-967093)

8 Willis D, Mason H, Gilling-Smith C \& Franks S. Modulation by insulin of follicle-stimulating hormone and luteinizing hormone actions in human granulosa cells of normal and polycystic ovaries. Journal of Clinical Endocrinology and Metabolism 199681 302-309. (https://doi.org/10.1210/jcem.81.1.8550768)

9 Dunaif A, Segal KR, Futterweit W \& Dobrjansky A. Profound peripheral insulin resistance, independent of obesity, in polycystic ovary syndrome. Diabetes 198938 1165-1174. (https://doi. org/10.2337/diab.38.9.1165)

10 Stepto NK, Cassar S, Joham AE, Hutchison SK, Harrison CL, Goldstein RF \& Teede HJ. Women with polycystic ovary syndrome have intrinsic insulin resistance on euglycaemic-hyperinsulaemic clamp. Human Reproduction 201328 777-784. (https://doi. org/10.1093/humrep/des463)

11 Boomsma CM, Eijkemans MJ, Hughes EG, Visser GH, Fauser BC \& Macklon NS. A meta-analysis of pregnancy outcomes in women with polycystic ovary syndrome. Human Reproduction Update 200612 673-683. (https://doi.org/10.1093/humupd/dml036)

12 Palomba S, de Wilde MA, Falbo A, Koster MP, La Sala GB \& Fauser BC. Pregnancy complications in women with polycystic ovary syndrome. Human Reproduction Update 201521 575-592. (https://doi. org/10.1093/humupd/dmv029)

13 Matthews DR, Hosker JP, Rudenski AS, Naylor BA, Treacher DF \& Turner RC. Homeostasis model assessment: insulin resistance and beta-cell function from fasting plasma glucose and insulin concentrations in man. Diabetologia 198528 412-419. (https://doi. org/10.1007/BF00280883)

14 de Wilde MA, Goverde AJ, Veltman-Verhulst SM, Eijkemans MJ, Franx A, Fauser BC \& Koster MP. Insulin action in women with polycystic ovary syndrome and its relation to gestational diabetes. Human Reproduction 201530 1447-1453. (https://doi.org/10.1093/ humrep/dev072)

15 de Wilde MA, Veltman-Verhulst SM, Goverde AJ, Lambalk CB, Laven JS, Franx A, Koster MP, Eijkemans MJ \& Fauser BC. Preconception predictors of gestational diabetes: a multicentre prospective cohort study on the predominant complication of pregnancy in polycystic ovary syndrome. Human Reproduction 2014 29 1327-1336. (https://doi.org/10.1093/humrep/deu077)

16 Catalano PM. Trying to understand gestational diabetes. Diabetic Medicine 201431 273-281. (https://doi.org/10.1111/dme.12381)
17 Gudmundsson S, Henningsson AC \& Lindqvist P. Correlation of birth injury with maternal height and birthweight. BJOG 2005112 764-767. (https://doi.org/10.1111/j.1471-0528.2004.00545.x)

18 HAPO Study Cooperative Research Group, Metzger BE, Lowe LP, Dyer AR, Trimble ER, Chaovarindr U, Coustan DR, Hadden DR, McCance DR, Hod M, et al. Hyperglycemia and adverse pregnancy outcomes. New England Journal of Medicine 2008358 1991-2002. (https://doi.org/10.1056/NEJMoa0707943)

19 Koninger A, Edimiris P, Koch L, Enekwe A, Lamina C, KasimirBauer S, Kimmig R \& Dieplinger H. Serum concentrations of afamin are elevated in patients with polycystic ovary syndrome. Endocrine Connections 20143 120-126. (https://doi.org/10.1530/EC-14-0053)

20 Koninger A, Mathan A, Mach P, Frank M, Schmidt B, Schleussner E, Kimmig R, Gellhaus A \& Dieplinger H. Is afamin a novel biomarker for gestational diabetes mellitus? A pilot study. Reproductive Biology and Endocrinology 201816 30. (https://doi.org/10.1186/ s12958-018-0338-x)

21 Lichenstein HS, Lyons DE, Wurfel MM, Johnson DA, McGinley MD, Leidli JC, Trollinger DB, Mayer JP, Wright SD \& Zukowski MM. Afamin is a new member of the albumin, a-fetoprotein, and vitamin D-binding protein gene family. Journal of Biological Chemistry 1994 269 18149-18154.

22 Voegele AF, Jerkovic L, Wellenzohn B, Eller P, Kronenberg F, Liedl KR \& Dieplinger H. Characterization of the vitamin E-binding properties of human plasma afamin. Biochemistry 200241 14532-14538. (https://doi.org/10.1021/bi026513v)

23 Ricciarelli R, Zingg JM \& Azzi A. Vitamin E 80th anniversary: a double life, not only fighting radicals. IUBMB Life 200152 71-76. (https://doi.org/10.1080/15216540252774801)

24 Heiser M, Hutter-Paier B, Jerkovic L, Pfragner R, Windisch M, BeckerAndre $\mathrm{M} \&$ Dieplinger H. Vitamin E binding protein afamin protects neuronal cells in vitro. Journal of Neural Transmission: Supplementa 2002 (Supplement 62) 337-345.

25 Gonzalez F, Minium J, Rote NS \& Kirwan JP. Hyperglycemia alters tumor necrosis factor-alpha release from mononuclear cells in women with polycystic ovary syndrome. Journal of Clinical Endocrinology and Metabolism 200590 5336-5342. (https://doi org/10.1210/jc.2005-0694)

26 Gonzalez F, Rote NS, Minium J \& Kirwan JP. Increased activation of nuclear factor kappaB triggers inflammation and insulin resistance in polycystic ovary syndrome. Journal of Clinical Endocrinology and Metabolism 200691 1508-1512. (https://doi.org/10.1210/jc.20052327)

27 Gonzalez F, Rote NS, Minium J \& Kirwan JP. Reactive oxygen speciesinduced oxidative stress in the development of insulin resistance and hyperandrogenism in polycystic ovary syndrome. Journal of Clinical Endocrinology and Metabolism 200691 336-340. (https://doi. org/10.1210/jc.2005-1696)

28 Kleinwechter H, Schafer-Graf U, Buhrer C, Hoesli I, Kainer F, Kautzky-Willer A, Pawlowski B, Schunck K, Somville T, Sorger M, et al. Gestational diabetes mellitus (GDM) diagnosis, therapy and follow-up care: practice guideline of the German Diabetes Association (DDG) and the German Association for Gynaecologyand Obstetrics (DGGG). Experimental and Clinical Endocrinology and Diabetes 2014122 395-405. (https://doi. org/10.1055/s-0034-1366412)

29 Ferriman D \& Gallwey JD. Clinical assessment of body hair growth in women. Journal of Clinical Endocrinology and Metabolism 196121 1440-1447. (https://doi.org/10.1210/jcem-21-11-1440)

30 Ludwig E. Classification of the types of androgenetic alopecia (common baldness) occurring in the female sex. British Journal of Dermatology 197797 247-254. (https://doi. org/10.1111/j.1365-2133.1977.tb15179.x)

31 Bonifacio M, Bradley CK, Karia S, Livingstone M, Bowman MC \& McArthur SJ. The original Beckman Coulter Generation II assay significantly underestimates AMH levels compared with the revised

This work is licensed under a Creative Commons Attribution-NonCommercial-NoDerivatives 4.0 Internationab sicense.ifica . com at 04/26/2023 07:27:31AM 
protocol. Journal of Assisted Reproduction and Genetics 201532 1691-1696. (https://doi.org/10.1007/s10815-015-0579-y)

32 Dieplinger B, Egger M, Gabriel C, Poelz W, Morandell E, Seeber B, Kronenberg F, Haltmayer M, Mueller T \& Dieplinger H. Analytical characterization and clinical evaluation of an enzyme-linked immunosorbent assay for measurement of afamin in human plasma. Clinica Chimica Acta: International Journal of Clinical Chemistry 2013 425 236-241. (https://doi.org/10.1016/j.cca.2013.08.016)

33 Youden WJ. Index for rating diagnostic tests. Cancer 19503 32-35. (https://doi.org/10.1002/1097-0142(1950)3:1<32::AIDCNCR2820030106>3.0.CO;2-3)

34 R Core Team. A Language and Environment for Statistical Computing: Vienna, Austria: R Foundation for Statistical Computing, 2014

35 Wei D, Zhang B, Shi Y, Zhang L, Zhao S, Du Y, Xu L, Legro RS, Zhang $\mathrm{H} \&$ Chen ZJ. Effect of preconception impaired glucose tolerance on pregnancy outcomes in women With polycystic ovary syndrome. Journal of Clinical Endocrinology and Metabolism 2017102 3822-3829. (https://doi.org/10.1210/jc.2017-01294)

36 Xia H, Zhang R, Sun X, Wang L \& Zhang W. Valuable predictors of gestational diabetes mellitus in infertile Chinese women with polycystic ovary syndrome: a prospective cohort study. Gynecological Endocrinology 201733 448-451. (https://doi.org/10.1080/09513590.2 $017.1290074)$

37 Cundy T, Gamble G, Neale L, Elder R, McPherson P, Henley P \& Rowan J. Differing causes of pregnancy loss in type 1 and type 2 diabetes. Diabetes Care 200730 2603-2607. (https://doi.org/10.2337/ dc07-0555)

38 Nawaz FH, Khalid R, Naru T \& Rizvi J. Does continuous use of metformin throughout pregnancy improve pregnancy outcomes in women with polycystic ovarian syndrome? Journal of Obstetrics and Gynaecology Research 200834 832-837. (https://doi.org/10.1111/ j.1447-0756.2008.00856.x)

39 Dong ZG, Beischer NA, Wein P \& Sheedy MT. Value of early glucose tolerance testing in women who had gestational diabetes in their previous pregnancy. Australian and New Zealand Journal of Obstetrics and Gynaecology 199333 350-357. (https://doi.org/10.1111/j.1479828X.1993.tb02107.x)

40 Glueck CJ, Wang P, Kobayashi S, Phillips H \& Sieve-Smith L. Metformin therapy throughout pregnancy reduces the development of gestational diabetes in women with polycystic ovary syndrome. Fertility and Sterility 200277 520-525. (https://doi.org/10.1016/ S0015-0282(01)03202-2)

41 Vanky E, Stridsklev S, Heimstad R, Romundstad P, Skogoy K, Kleggetveit O, Hjelle S, von Brandis P, Eikeland T, Flo K, et al. Metformin versus placebo from first trimester to delivery in polycystic ovary syndrome: a randomized, controlled multicenter study. Journal of Clinical Endocrinology and Metabolism 201095 E448-E455. (https://doi.org/10.1210/jc.2010-0853)

42 Kollerits B, Lamina C, Huth C, Marques-Vidal P, Kiechl S, Seppala I, Cooper J, Hunt SC, Meisinger C, Herder C, et al. Plasma concentrations of afamin are associated With prevalent and incident Type 2 diabetes: a pooled analysis in more than 20,000 individuals. Diabetes Care 2017 40 1386-1393. (https://doi.org/10.2337/dc17-0201)

43 Kronenberg F, Kollerits B, Kiechl S, Lamina C, Kedenko L, Meisinger C, Willeit J, Huth C, Wietzorrek G, Altmann ME, et al. Plasma concentrations of afamin are associated with the prevalence and development of metabolic syndrome. Circulation: Cardiovascular Genetics 20147 822-829. (https://doi.org/10.1161/ CIRCGENETICS.113.000654)

44 Shen CT, Wei WJ, Qiu ZL, Song HJ \& Luo QY. Afamin promotes glucose metabolism in papillary thyroid carcinoma. Molecular and Cellular Endocrinology 2016434 108-115. (https://doi.org/10.1016/j. mce.2016.06.013)

45 Jerkovic L, Voegele AF, Chwatal S, Kronenberg F, Radcliffe CM, Wormald MR, Lobentanz EM, Ezeh B, Eller P, Dejori N, et al. Afamin is a novel human vitamin E-binding glycoprotein characterization and in vitro expression. Journal of Proteome Research 20054 889-899. (https://doi.org/10.1021/pr0500105)

46 Hubalek M, Buchner H, Mortl MG, Schlembach D, Huppertz B, Firulovic B, Kohler W, Hafner E, Dieplinger B, Wildt L, et al. The vitamin E-binding protein afamin increases in maternal serum during pregnancy. Clinica Chimica Acta: International Journal of Clinical Chemistry 2014434 41-47. (https://doi.org/10.1016/j. cca.2014.03.036)

47 Jensterle M, Weber M, Pfeifer M, Prezelj J, Pfutzner A \& Janez A. Assessment of insulin resistance in young women with polycystic ovary syndrome. International Journal of Gynaecology and Obstetrics 2008102 137-140. (https://doi.org/10.1016/j.ijgo.2008.03.017)

Received in final form 26 March 2019

Accepted 16 April 2019

Accepted Preprint published online 16 April 2019 https://ec.bioscientifica.com https://doi.org/10.1530/EC-19-0064 (c) 2019 The authors Published by Bioscientifica Ltd
This work is licensed under a Creative Commons Attribution-NonCommercial-NoDerivatives 4.0 Internationab sicense.ifica . com at 04/26/2023 07:27:31AM 